\title{
Emergency consultations for male adolescents: Somatic and psychological characteristics and profiles of regular users. A retrospective chart review
}

\section{A. Forestier ${ }^{\mathrm{a}, \mathrm{b}, *}$}

aline.forestier@unil.ch

\section{Gehri}

O. Guilbaud ${ }^{d}$

\section{A.S. Ramelet}

aUniversity institute of higher education and research in healthcare, Biopôle 2, route de la Corniche 10, 1010 Lausanne, Switzerland

bSchool of health sciences, Avenue de Champel 47, 1206 Geneva, Switzerland

'Department woman, mother, child, University Hospital of Lausanne, Rue du Bugnon, 1010 Lausanne, Switzerland

dUniversity hospital of Lausanne, service universitaire de psychiatrie de l'enfant et de l'adolescent (SUPEA), 1010 Lausanne, Switzerland

*Corresponding author at: IUFRS, Route de la Corniche 10, Lausanne, 1010, Switzerland.
Published in Archives de Pédiatrie, 2019, vol. 26 no. 7,

p. 393-399 which should be cited

to refer to this work

DOI : $10.1016 / j . a r c p e d .2019 .08 .009$

\section{Abstract}

Introduction

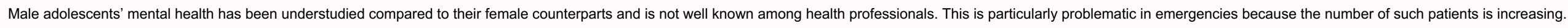
Objectives

To identify the type of demand for care and the characteristics of male adolescents' emergency room visits. To describe the sociodemographic data and clinical characteristics of regular users.

Method

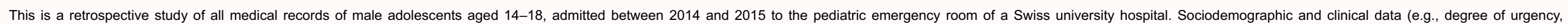
diagnosis, length of stay, emergency service use, and emergency discharge destinations) were collected. Descriptive and multivariate analyses were performed using STATA 13.1 software.

Results

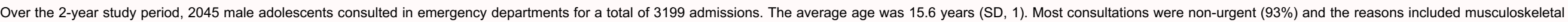

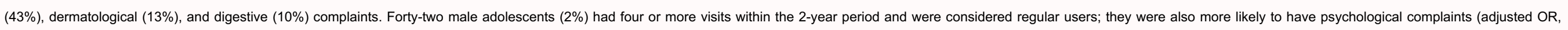
$5.04 ; 95 \% \mathrm{Cl}, 1.81-13.72$ ) and comorbidities (adjusted $\mathrm{OR}, 2.55 ; 95 \% \mathrm{Cl}, 1.25-5.21$ ) when compared to their counterparts with fewer than four visits. Conclusion

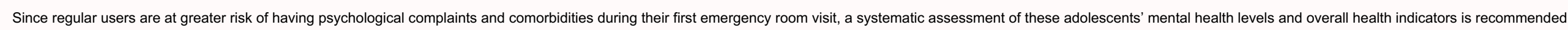

Keywords: Adolescent; Pediatric emergency medicine; Nursing care; Health service; Mental health

\section{Introduction}

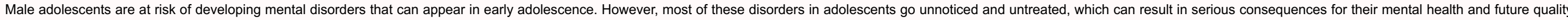

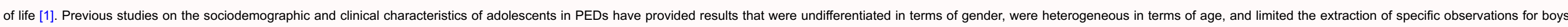




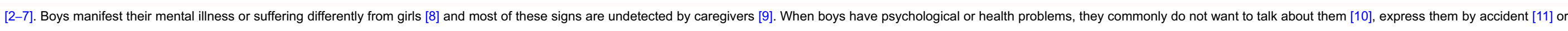

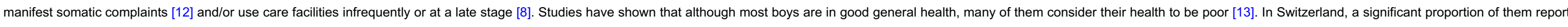

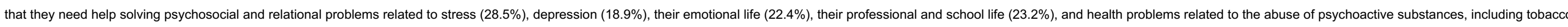

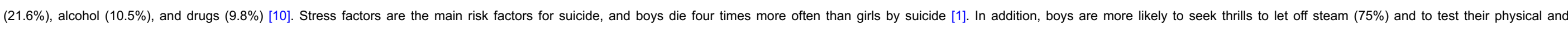
psychological limits (44.3\%), and they are attracted to dangerous situations (42\%) and sports (47.7\%) [10].

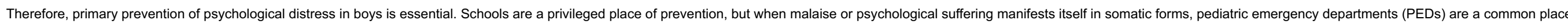
to turn to and seem to be the ideal place to detect psychological disorders early and set up specific universal prevention measures.

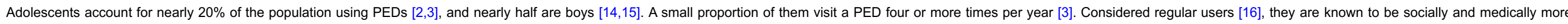
vulnerable, especially if they present with psychiatric symptoms $[14,17]$

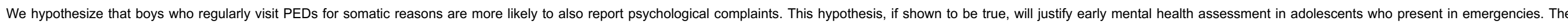
results of this study will help better understand the reasons why they come to the emergency room and what their orientations are.

The purposes of this study were to:

- identify the nature of the demand and characteristics of boys' emergency consultations;

- describe the sociodemographic data and clinical characteristics of male regular users.

\section{Materials and methods}

\subsection{Context}

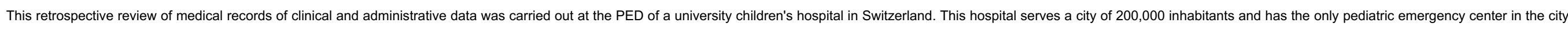

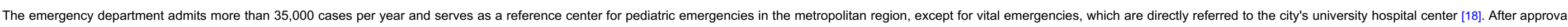
by the Cantonal Ethics Committee on Human Research and anonymization of the data, all of the medical files of boys aged 14-18 years old, who consulted the PED between 1 January 2014 and 31 December 2015, were obtained.

\subsection{Research variables}

Three types of variables were collected:

- sociodemographic variables, including age, sex, and continent and country of origin;

- clinical variables, including the Australasian Triage Scale (ATS) (degree of emergency) [19] and reasons for consultation according to the International Classification of Primary Care Version 2 (ICPC-2) [20];

- consultation characteristics, including the date and time of consultation admission, emergency watiting time, recurrent visits, referrals, and destinations after ED discharge.

The reasons for consultation were coded according to the ICPC-2 by the first author (AF) and a research assistant for all admissions; the codes were compared and a final choice was made

\subsection{Statistical analyses}

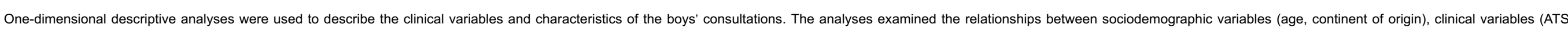

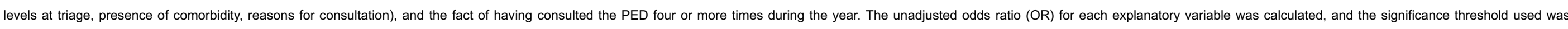

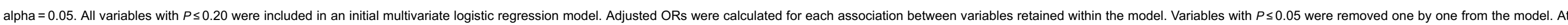

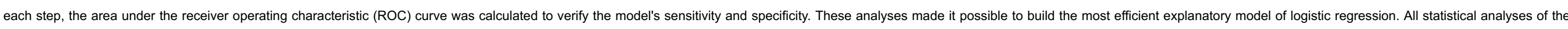
data were carried out using Stata 13.1 software (2013). 


\section{Results}

\subsection{Sociodemographic variables}

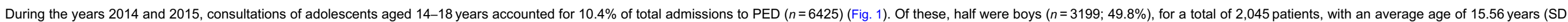
1.06). The boys:

- for the most part came from Europe $(n=2723 ; 85.1 \%)$, including $61.4 \%$ Swiss $(n=1672)$

- $6.2 \%(n=222)$ were African;

- came from the Americas $(n=128,4 \%)$, with $88.3 \%(n=113)$ South American;

- iv) $3.8 \%(n=123)$ came from Asia-Oceania.

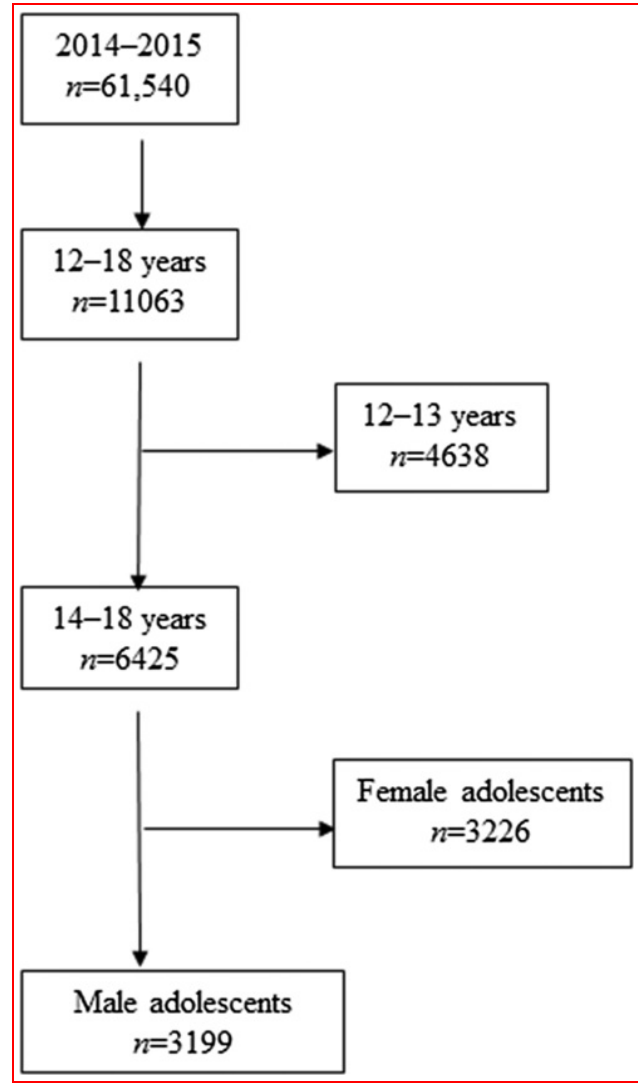

Fig. 1 Flow chart. PED: pediatric emergency department.

\subsection{Clinical variables}

\subsubsection{Clinical evaluation at triage}

At triage, the majority of the boys admitted $(93 \%, n=2968)$ had a nonurgent or semiurgent clinical condition (ATS triage score 4 or 5 ). 


\subsubsection{Reasons for consultation}

The top five reasons for consultation on the CISP-2 classification were complaints or symptoms of the following systems:

- musculoskeletal $(n=1366 ; 42.8 \%)$

- dermatological $(n=412 ; 12.9 \%)$;

- respiratory $(n=386 ; 12.1 \%$ );

- digestive $(n=324 ; 10.1 \%)$;

- neurological $(n=150 ; 4.7 \%)$

Complaints or symptoms of psychological suffering concerned $2.7 \%(n=85)$ of the boys consulting at the PED. The distributions of age and the reasons for consultation distributions were significantly different $(P=0.000)(F i g .2)$.

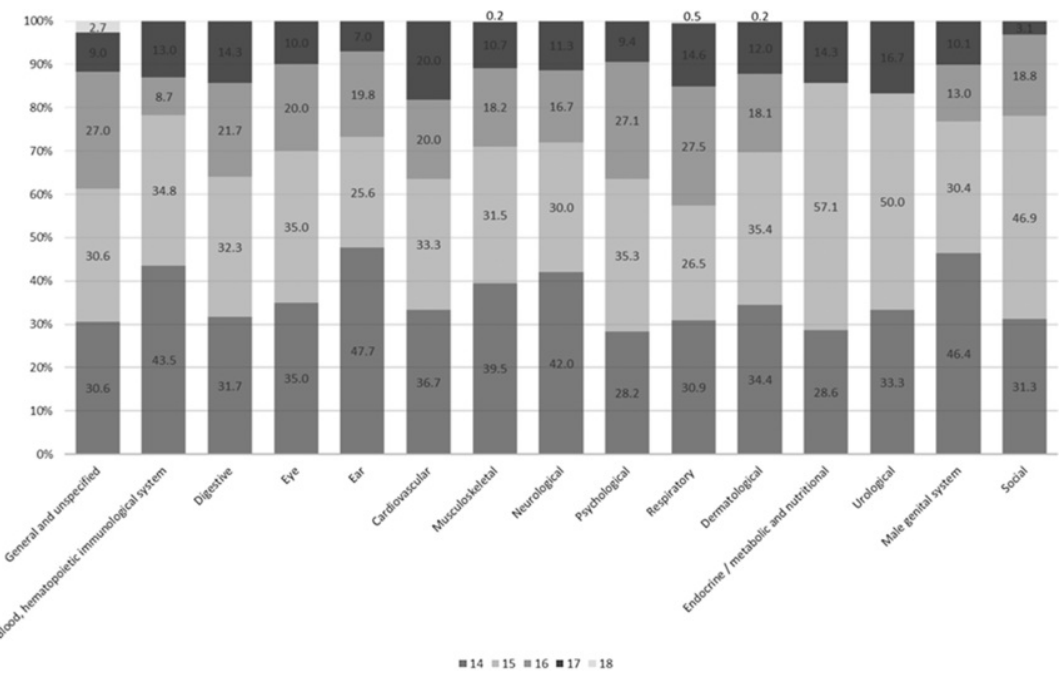

Fig. 2 Distribution of reasons for consultations by age $(\%)(n=3199)$

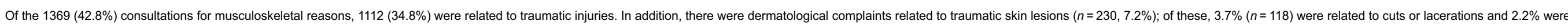

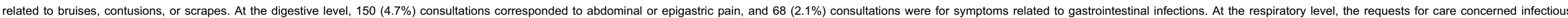

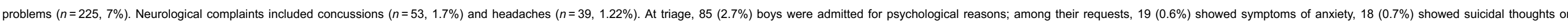

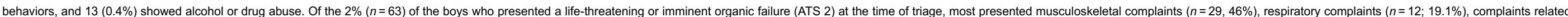
to the male reproductive system $(n=7 ; 11.1 \%)$, or psychological complaints $(n=4 ; 6.3 \%)$.

\subsubsection{Variables of consultation characteristics}

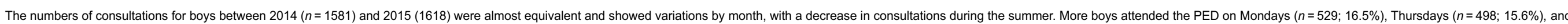
Tuesdays ( $n=491 ; 15.3 \%$ ). Half of the boys' consultations were between $12 \mathrm{pm}$ and $7 \mathrm{pm}$ (median, $4 \mathrm{pm}$ ).

\subsubsection{Duration of care}

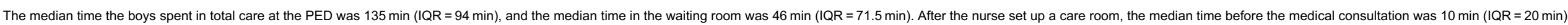




\subsubsection{Orientation}

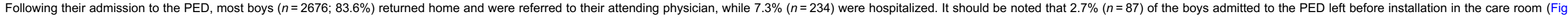

3).

2000

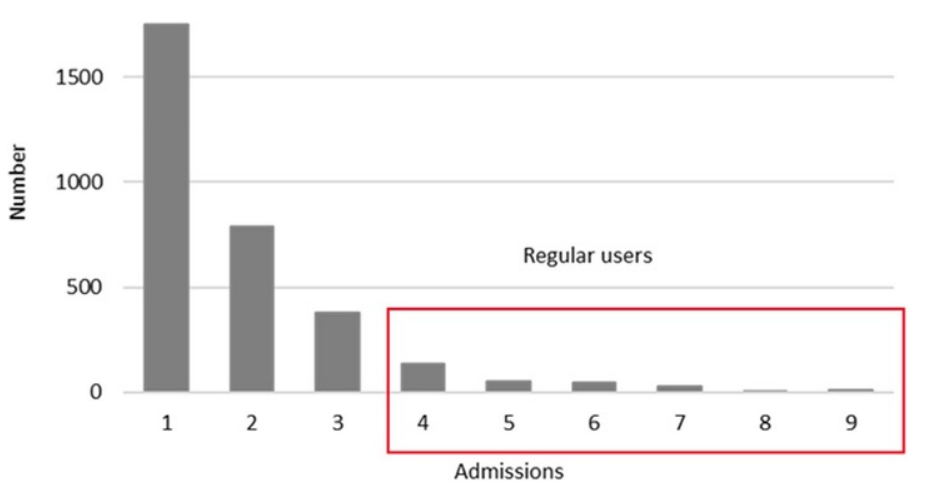

Fig. 3 Number of admissions to PED per year between 2014 and 2015 ( $n=3199)$. PED: pediatric emergency department.

\subsubsection{Recurring visits and regular users}

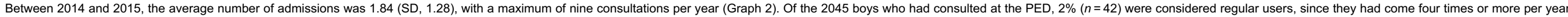

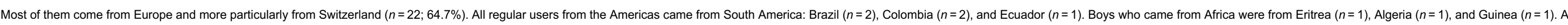

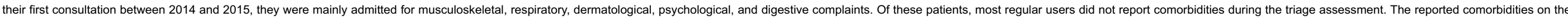
first visit to PED were allergies, a history of musculoskeletal injuries or trauma and unspecified surgical procedures, asthma, infectious pathologies, or sequelae of neurological infections, social reasons, or psychiatric symptoms (Table 1).

Table 1 Sociodemographic variables, reasons for consultations and comorbidity characterizing regular $(n=42)$ and nonregular users $(n=2003)$

\section{alt-text: Table 1}

\begin{tabular}{|c|c|c|}
\hline & Regular users $n(\%)$ & Non-regular users $n(\%)$ \\
\hline \multicolumn{3}{|l|}{ Age group } \\
\hline 14 years old & $24(57.4)$ & $844(42.1)$ \\
\hline 15 years old & $10(23.8)$ & $607(30.3)$ \\
\hline 16 years old & $6(14.3)$ & $345(17.2)$ \\
\hline 17 years old & $2(4.76)$ & $192(9.6)$ \\
\hline 18 years old & - & $7(0.4)$ \\
\hline \multicolumn{3}{|l|}{ Continent of origin } \\
\hline Africa & $3(2.1)$ & $140(7)$ \\
\hline Americas & $5(11.9)$ & $70(3.5)$ \\
\hline Asia-Oceania & - & $88(4.4)$ \\
\hline Europe & $34(81)$ & $1703(85.2)$ \\
\hline
\end{tabular}




\begin{tabular}{|c|c|c|}
\hline \multicolumn{3}{|l|}{ Reason for consultation } \\
\hline Blood, hematopoietic immunological system & $1(2.4)$ & $14(0.7)$ \\
\hline Digestive system & $3(7.1)$ & $176(8.8)$ \\
\hline Ear & $2(4.8)$ & $62(3.1)$ \\
\hline Musculoskeletal & $15(35.7)$ & $900(44.9)$ \\
\hline Neurological & $1(2.4)$ & $107(5.3)$ \\
\hline Psychological & $5(11.9)$ & $45(2.3)$ \\
\hline Respiratory & $7(16.7)$ & $235(11.7)$ \\
\hline Dermatological & $6(14.3)$ & $262(13.1)$ \\
\hline Male genital system & $1(2.4)$ & $46(2.3)$ \\
\hline Eyes & - & $13(0.7)$ \\
\hline Cardiovascular & - & $10(0.5)$ \\
\hline Endocrine/metabolic and nutritional & - & $6(0.3)$ \\
\hline Urological & - & $11(0.6)$ \\
\hline \multicolumn{3}{|l|}{ Comorbidity } \\
\hline No comorbidity & $31(73.8)$ & $1,787(89.2)$ \\
\hline Unspecified surgical procedures & $1(2.4)$ & $18(1)$ \\
\hline Asthma & $1(2.4)$ & $55(2.7)$ \\
\hline Allergies & $3(7.1)$ & $41(0.1)$ \\
\hline Infectious disease & $1(2.38)$ & $7(0.35)$ \\
\hline Psychological troubles & $1(2.4)$ & $11(0.6)$ \\
\hline Musculoskeletal injuries or trauma & $2(4.8)$ & $8(0.4)$ \\
\hline Neurological infections and epilepsy & $1(2.4)$ & $14(0.7)$ \\
\hline Social reasons and aggression & $1(2.4)$ & $1(0.1)$ \\
\hline Diabetes and metabolic disease & - & $15(0.8)$ \\
\hline Digestive pathology & - & $5(0.3)$ \\
\hline Cardiac pathology & - & $12(0.6)$ \\
\hline Kidney or urinary pathology & - & $5(0.3)$ \\
\hline Cancer and genetic disease & - & $6(0.4)$ \\
\hline Disability & - & $13(0.7)$ \\
\hline Dermatological disease & - & $2(0.1)$ \\
\hline ENT and respiratory pathology & - & $6(0.3)$ \\
\hline Male genital system & - & $1(0.1)$ \\
\hline
\end{tabular}

ENT: ear, nose, and throat. Missing values: non-regular users - age group $(n=8)$, continent of origin $(n=2)$, comorbidity $(n=7)$. 
Table 2 Relationships between the sociodemographic and clinical variables for regular users $(n=42)$.

alt-text: Table 2

\begin{tabular}{|c|c|c|c|}
\hline Characteristics & Unadjusted OR & $P$ & $95 \% \mathrm{Cl}$ \\
\hline Age & 0.76 & 0.108 & $0.56-1.06$ \\
\hline Presence of comorbidity & 2.80 & 0.004 & $1.40-5.66$ \\
\hline \multicolumn{4}{|l|}{ ATS level of triage } \\
\hline ATS4 & 2.41 & 0.011 & $1.22-4.78$ \\
\hline ATS5 & 1 (Réf) & & \\
\hline \multicolumn{4}{|l|}{ Continental origin } \\
\hline Africa & 1.07 & 0.907 & $0.32-3.54$ \\
\hline Americas & 3.57 & 0.01 & $1.36-9.42$ \\
\hline Europe & 1 (Réf) & & \\
\hline \multicolumn{4}{|l|}{ Reason for consultation } \\
\hline Blood, hematopoietic immunological system & 3.46 & 0.23 & $0.44-26.97$ \\
\hline Digestive & 0.79 & 0.71 & $0.24-2.61$ \\
\hline Ear & 1.56 & 0.54 & $0.37-6.62$ \\
\hline Musculoskeletal & 0.68 & 0.23 & $0.36-1.29$ \\
\hline Neurological & 0.43 & 0.40 & $0.059-3.17$ \\
\hline Psychological & 5.87 & $<0.001$ & $2.21-15.66$ \\
\hline Respiratory & 1.50 & 0.33 & $0.66-3.43$ \\
\hline Dermatological & 1.10 & 0.81 & $0.46-2.65$ \\
\hline Male genital system & 1.03 & 0.97 & $0.14-7.70$ \\
\hline
\end{tabular}

ATS: Australasian triage scale; OR: odds ratio; Cl: confidence interval.

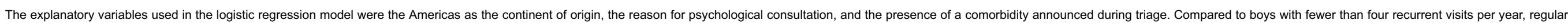

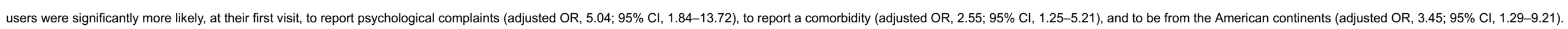

\section{Discussion}

To our knowledge, this study is the first to characterize the sociodemographic and clinical profiles of boys who are considered regular users of a PED. We examined the reasons for admission and the characteristics of their consultations.

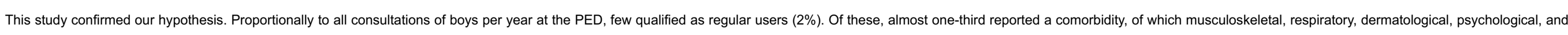

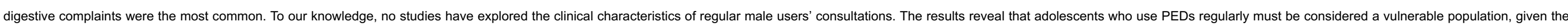
complexity of their social, mental, and somatic situation [3,14].

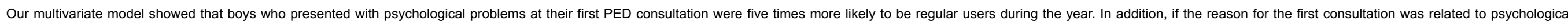




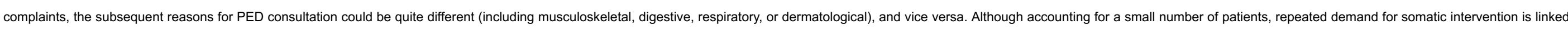

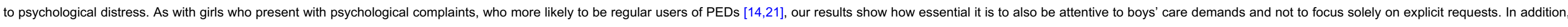

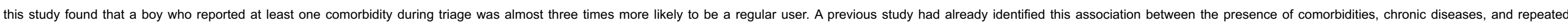

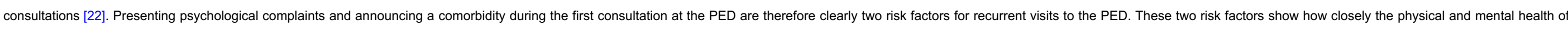

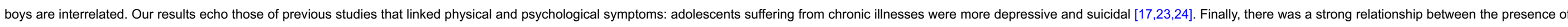

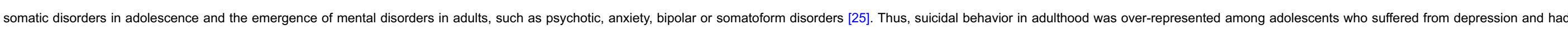

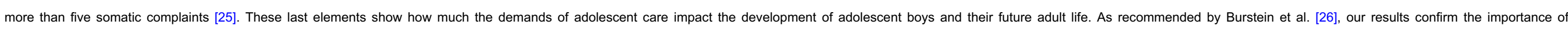

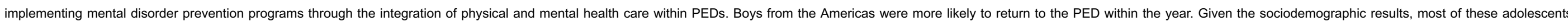

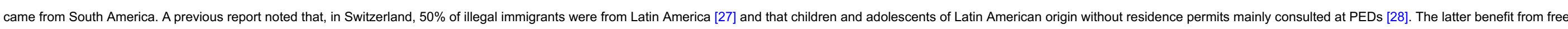

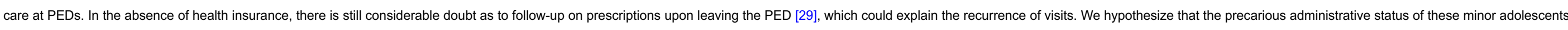
constitutes significant vulnerability and impacts the use of PEDs, which remain a favorable place for primary care because of their accessibility and the multidisciplinary care offered with the support of a translator-mediator.

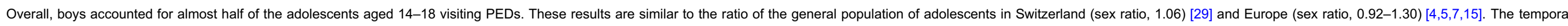

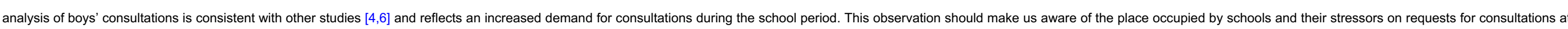

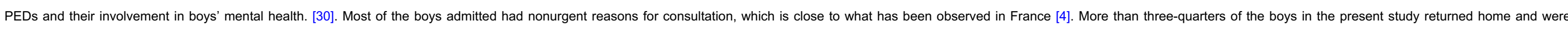

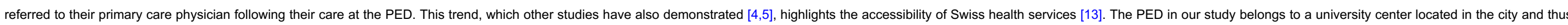

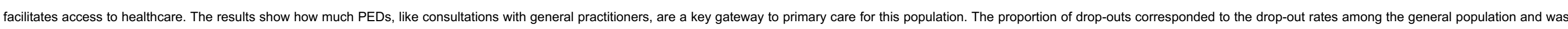

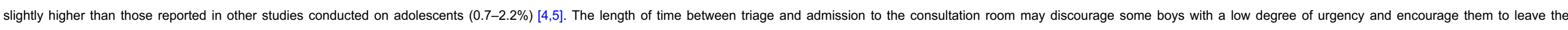

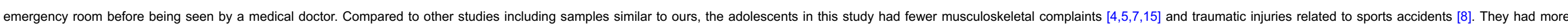

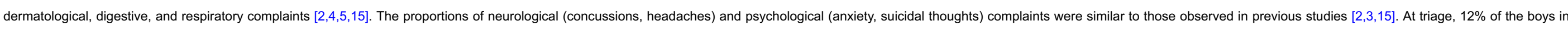

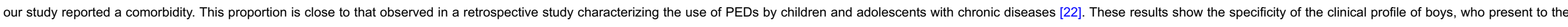

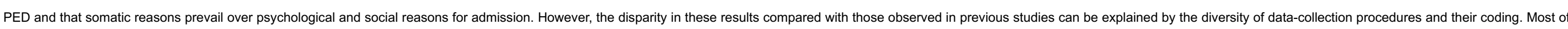

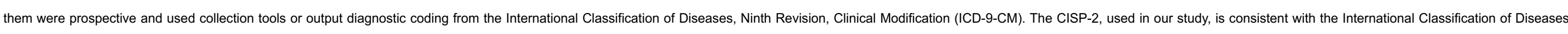
Ten (ICD-10) and allows for different coding of the reasons for consulting male adolescents.

\subsection{Strengths and limitations}

This study is the first to identify the many explanatory variables of boys' consultations at PEDs and the risk factors for recurrent visits to PEDs. These results are reinforced by the size of the sample ( $n=3199$ ).

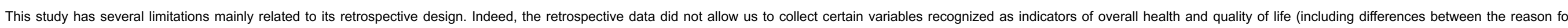

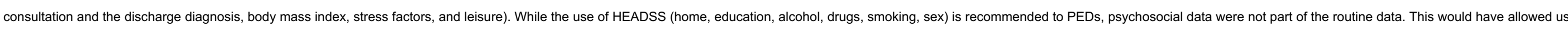

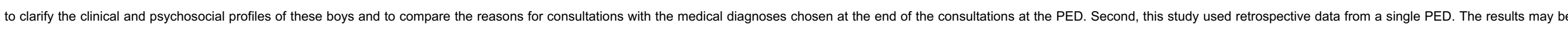

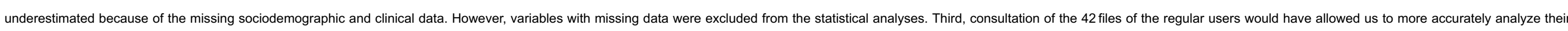

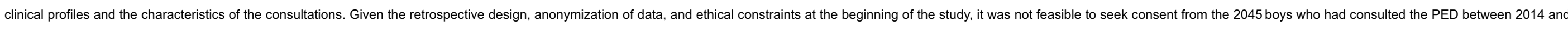

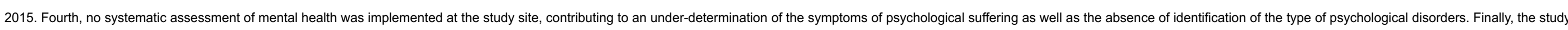
did not identify whether boys referred to their attending physician had actually contacted their physician.

\subsection{Recommendations}

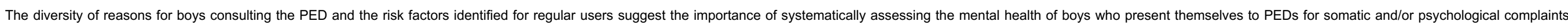

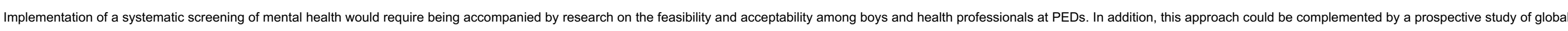

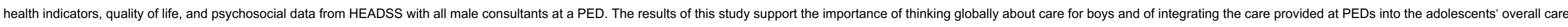




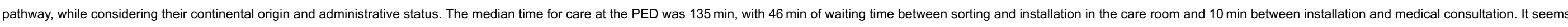

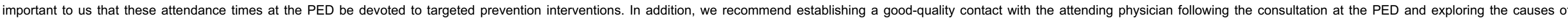
disruptions in care after the PED visit and in the health follow-up.

\section{Conclusion}

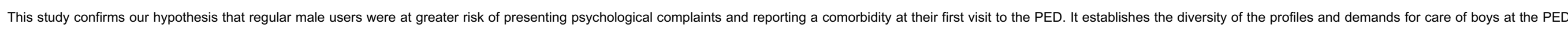

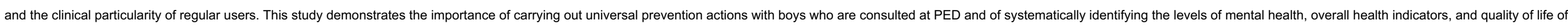
boys who use PEDs regularly.

\section{Funding}

None.

\section{Disclosure of interest}

The authors declare that they have no competing interest.

\section{Acknowledgements}

This study was supported by the HES-SO University of Applied Sciences and Arts Western Switzerland, School of Health Sciences, Geneva, Switzerland.

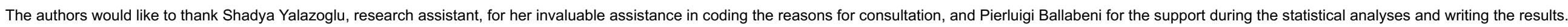

\section{References}

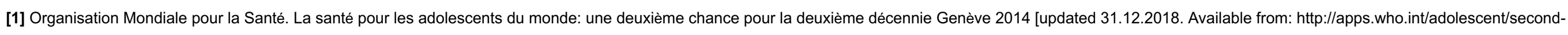
decade/files/WHO_FWC_MCA_14.05_fre.pdf.

[2] E.R. Alpern, R.M. Stanley, M.H. Gorelick, et al., Epidemiology of a pediatric emergency medicine research network: the PECARN Core Data Project, Pediatr Emerg Care 22, 2006, 689-699.

[3] E.R. Alpern, A.E. Clark, E.A. Alessandrini, et al., Recurrent and high-frequency use of the emergency department by pediatric patients, Acad Emerg Med 21, 2014, 365-373.

[4] P. Velin, H. Alamir, P. Babe, et al., Les adolescents aux urgences de l'hôpital Lenval pour enfants à Nice en 1999, Arch Pediatr 8, 2001, 361-367.

[5] C. Stheneur, M. Sznajder, C. Guyot, et al., Les urgences, un lieu de repérage des adolescents en difficulté, Arch Pediatr 21, 2014, 593-600.

[6] M.A. Podlipski, A.C. Peuch, V. Belloncle, et al., Accueil en urgence des adolescents pour motif pédopsychiatrique, Arch Pediatr 21, 2014, 7-12.

[7] P. Vic, E. Ramé, A. Robert-Dehault, et al., Repérage des conduites à risque et des symptômes dépressifs chez les adolescents admis en service d'accueil des urgences, Arch Pediatr 22, $2015,580-594$.

[8] A.V. Marcell, J.D. Klein, I. Fischer, et al., Male adolescent use of health care services: where are the boys?, J Adolesc Health 30, 2002, 35-43.

[9] V.A. Downey and L.S. Zun, Identifying Undiagnosed Pediatric Mental Illness in the Emergency Department, Pediatr Emerg Care 34, 2018, e21-e23.

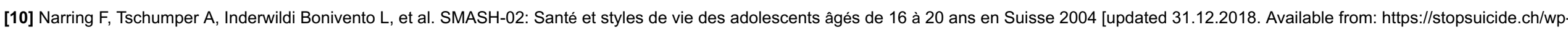
content/uploads/2017/07/smash_rapport_fr.pdf.

[11] D. Marcelli, P. Ingrand, I. Ingrand, et al., Échelle d'évaluation du risque de récidive (ecarr). Étude de validation prospective d'une répétition d'accident, La psychiatrie de l'enfant 54, 2011 , 253-299.

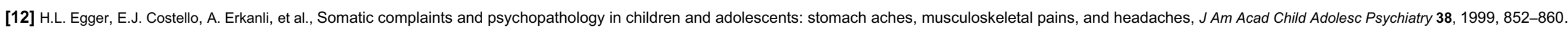

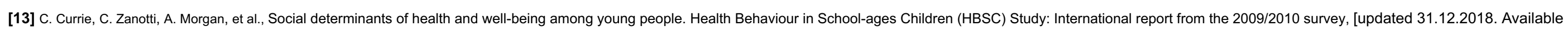


from: http://www.euro.who.int/_data/assets/pdf_file/0003/163857/Social-determinants-of-health-and-well-being-among-young-people.pdf.2012, WHO Regional Office for Europe.

[14] E. Mapelli, T. Black and Q. Doan, Trends in Pediatric Emergency Department Utilization for Mental Health-Related Visit, J Pediatr 167, 2015, 905-910.

[15] A. Ziv, J.R. Boulet and G.B. Slap, Emergency department utilization by adolescents in the United States, Pediatrics 101, 1998, 987-994.

[16] T.E. Locker, S. Baston, S.M. Mason, et al., Defining frequent use of an urban emergency department, Emerg Med J 24, 2007, $398-401$.

[17] J.J. Brennan, T.C. Chan, R.Y. Hsia, et al., Emergency department utilization among frequent users with psychiatric visits, Acad Emerg Med 21, 2014, $1015-1022$.

[18] Centre Hospitalier Universitaire Vaudois. Rapport d'activité 2016 [updated 23.09.2018. Available from: https://rapportsannuels.chuv.ch/activite/2016/

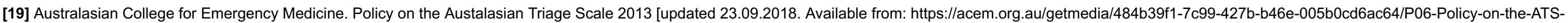
Jul-13-v04.aspx

[20] Jamoulle M, Roland M, Humbert J, et al. Traitement de l'information médicale par la Classification Internationale des Soins Primaires: CISP-2: deuxième version 2000 [updated 23.09.18. Available from: https://orbi.uliege.be/bitstream/2268/196337/1/cisp_bureau\%20fr.pdf.

[21] A.S. Newton, S. Ali, D.W. Johnson, et al., Who comes back?. Characteristics and predictors of return to emergency department services for pediatric mental health care, Acad Emerg Med 17, 2010, 177-186.

[22] L. O'Mahony, D.S. O'Mahony, T.D. Simon, et al., Medical complexity and pediatric emergency department and inpatient utilization, Pediatrics 131, 2013, e559-e565.

[23] A. Christin, C. Akre, A. Berchtold, et al., Parent-adolescent relationship in youths with a chronic condition, Child Care Health Dev 42, $2016,36-41$.

[24] C. Lidon-Moyano, D. Wiebe, P. Gruenewald, et al., Associations between self-harm and chronic disease among adolescents: Cohort study using statewide emergency department data, J Adolesc 72, $2019,132-140$.

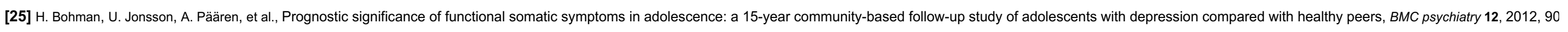

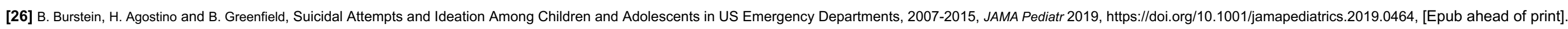

[27] Valli, M., Les migrants sans permis de séjour à Lausanne. Rapport rédigé à la demande de la Municipalité de Lausanne. 2003. [updated 07.12.2018. Available from: https://asile.ch/wp/wpcontent/uploads//06/RapportValli_SansPapiersLausanne.pdf 2003

[28] S.D. Depallens, M.J. Puelma, J.D. Krahenbuhl, et al., The health status of children without resident permit consulting the Children's Hospital of Lausanne, Swiss Med Wkly 140, 2010, w81304.

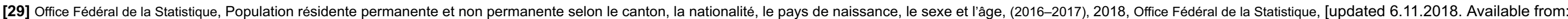
https://www.bfs.admin.ch/bfs/fr/home/statistiques/population.assetdetail.5887451.html.

[30] A.B. Goldstein, M.A. Silverman, S. Phillips, et al., Mental health visits in a pediatric emergency department and their relationship to the school calendar, Pediatr Emerg Care 21, 2005, 653-657.

\section{Queries and Answers}

Query: The author names have been tagged as given names and surnames (surnames are highlighted in teal color). Please confirm if they have been identified correctly.

Answer: Yes

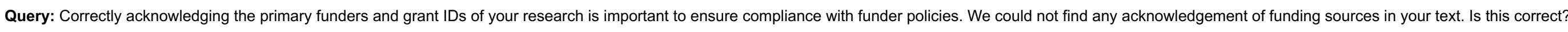
Answer: Yes

Query: Please note that figure 1 was not cited in the text. Please check that the citation suggested by the copyeditor are in the appropriate place, and correct if necessary.

Answer: OK

Query: Please provide journal title for references 1, 10, 20 and 27 
